\title{
Effects of a DVD-delivered randomized controlled physical activity intervention on functional health in cancer survivors
}

Elizabeth A. Salerno ${ }^{1 *}$ (D), Neha P. Gothe ${ }^{2,3}$, Jason Fanning ${ }^{4}$, Lindsay L. Peterson ${ }^{5}$, Graham A. Colditz ${ }^{1}$ and Edward McAuley ${ }^{2,3}$

\begin{abstract}
Background: Supervised physical activity interventions improve functional health during cancer survivorship, but remain costly and inaccessible for many. We previously reported on the benefits of a DVD-delivered physical activity program $\left(\right.$ FlexToBa $\left.^{\mathrm{TM}}\right)$ in older adults. This is a secondary analysis of the intervention effects among cancer survivors in the original sample.
\end{abstract}

Methods: Low active, older adults who self-reported a history of cancer ( $N=46 ; M$ time since diagnosis $=10.7 \pm 9.4$ years) participated in a 6-month, home-based physical activity intervention. Participants were randomized to either the DVD-delivered physical activity program focused on flexibility, toning, and balance (FlexToBa ${ }^{\mathrm{TM}} ; n=22$ ) or an attentional control condition $(n=24)$. Physical function was assessed by the Short Physical Performance Battery (SPPB) at baseline, end of intervention, and at 12 and 24 months after baseline.

Results: Repeated measures linear mixed models indicated a significant group*time interaction for the SPPB total score $(\beta=-1.14, p=0.048)$, driven by improved function from baseline to six months in the FlexTOBa ${ }^{\text {TM }}$ group. The intervention group also had improved balance $(\beta=-0.56, p=0.041)$ compared with controls. Similar trends emerged for the SPPB total score during follow-up; the group*time interaction from 0 to 12 months approached significance $(\beta=-0.97, p=0.089)$ and was significant from 0 to 24 months $(\beta=-1.84, p=0.012)$. No significant interactions emerged for other outcomes ( $p s>0.11$ ).

Conclusions: A DVD-delivered physical activity intervention designed for cancer-free older adults was capable of eliciting and maintaining clinically meaningful functional improvements in a subgroup of cancer survivors, with similar effects to the original full sample. These findings inform the dissemination of evidence-based physical activity programs during survivorship.

Trial registration: ClinicalTrials.govNCT01030419. Registered 11 December 2009

Keywords: Cancer, Exercise, Physical function, Physical activity, Survivorship, Telerehabilitation

\footnotetext{
* Correspondence: e.salerno@wustl.edu

1 Division of Public Health Sciences, Department of Surgery, Washington

University School of Medicine in St. Louis, St. Louis, USA

Full list of author information is available at the end of the article
}

(c) The Author(s). 2021 Open Access This article is licensed under a Creative Commons Attribution 4.0 International License, which permits use, sharing, adaptation, distribution and reproduction in any medium or format, as long as you give appropriate credit to the original author(s) and the source, provide a link to the Creative Commons licence, and indicate if changes were made. The images or other third party material in this article are included in the article's Creative Commons licence, unless indicated otherwise in a credit line to the material. If material is not included in the article's Creative Commons licence and your intended use is not permitted by statutory regulation or exceeds the permitted use, you will need to obtain permission directly from the copyright holder. To view a copy of this licence, visit http://creativecommons.org/licenses/by/4.0/ The Creative Commons Public Domain Dedication waiver (http://creativecommons.org/publicdomain/zero/1.0/) applies to the data made available in this article, unless otherwise stated in a credit line to the data. 


\section{Background}

There is a wealth of evidence for the benefits of physical activity during cancer survivorship, ranging from improved functional and psychosocial health to decreased risk of recurrence and mortality [1-4]. However, many of the existing evidence-based physical activity interventions after cancer have been supervised [1], requiring travel to a university or clinical setting. While such interventions are important for understanding physical activity's efficacy for improving health outcomes, their design inherently limits access for many survivors. Notably, these are individuals who may stand to benefit the most from such programs (e.g., sedentary or rural-dwelling survivors and those who are functionally impaired/disabled), highlighting the need for innovative, scalable physical activity interventions that can be disseminated to the broader population of cancer survivors [5].

As technology advances, these efforts have focused on developing and testing digitally-delivered physical activity interventions during cancer survivorship [6], with small but promising evidence for increased moderate-tovigorous physical activity (MVPA) [7]. However, many of these trials suffer from several limitations (e.g., single arm, no theoretical framework, short follow-up) that prevent us from understanding how best to implement physical activity in the home for increased physical activity and improved functional health $[7,8]$. Before designing new interventions, it is necessary to understand if existing evidence-based, high quality interventions in other populations can successfully increase physical activity and improve functional health in cancer survivors. Such analyses will better inform the design and implementation of cancer-specific trials. Given the accelerated aging phenotype often seen in cancer survivors $[9,10]$, the aging literature may be a suitable framework for such an analysis.

We previously conducted a DVD-delivered 6-month randomized controlled exercise intervention in older adults across the state of Illinois [11]. The Flexibility, Toning, and Balance Trial (FlexToBa ${ }^{\text {Tx }}$ ) is grounded in Social Cognitive Theory [12] with a Reach, Effectiveness, Adoption, Implementation, Maintenance (REAIM) framework [13], unique elements designed to influence public health [11]. Participants in the intervention arm evidenced significant improvements in functional health, self-esteem, anxiety and depressive symptoms, had reduced sedentary behavior, and maintained physical activity levels up to two years after the intervention compared with the control condition [14-21]. Notably, most of these effects were moderate in size with clinically meaningful implications. Flex$\mathrm{ToBa}^{\mathrm{TM}}$ has also been successfully delivered to individuals with Multiple Sclerosis (MS), with small to modest effects for improved functional health and quality of life, increased physical activity, and decreased sitting time in the intervention arm [22].

Cancer survivors are now living well into older adulthood, and there are real concerns about healthy aging in this population given the number of functional impairments that persist well into survivorship [23]. It is important to understand if and how physical activity interventions designed for older adults also extend to long-term survivors, or alternatively, require additional cancer-specific tailoring. FlexToBa ${ }^{\mathrm{TM}}$ was designed to be adaptable to different functional abilities, with robust effects both in older adults and clinical populations such as MS, and extensive reach [24]. Thus, FlexToBa ${ }^{\mathrm{TM}}$ is a good candidate intervention for determining the effects of an existing physical activity program in individuals with a history of cancer. To this end, we examined the effects of the intervention on functional health, physical activity, and sedentary behavior in participants from the original sample who self-reported a prior cancer diagnosis. We hypothesized that those in the intervention arm would exhibit similar effects as the full sample, such that survivors would demonstrate improved functional health, maintained physical activity levels, and reduced sedentary behavior at the end of the intervention and after a 12- and 24-month non-contact follow-up period.

\section{Methods}

Participants, Study Design \& Interventions

A comprehensive description of the FlexToBa $a^{\text {Ts }}$ trial, including eligibility criteria, randomization allocation, and intervention details, has been published previously [11]. Briefly, community-dwelling, low active older adults over the age of 65 years were recruited from 83 towns and cities across a 5000 mile $^{2}$ area of central Illinois to participate in a 6-month randomized controlled exercise trial examining the effects of a home-based physical activity intervention on physical activity, functional health, and quality of life. Participants $(N=307)$ were randomized to either the FlexToBa ${ }^{\mathrm{TM}}$ DVD intervention or a healthy aging DVD control condition. The present study represents a secondary analysis of participants who selfreported a history of cancer at baseline of the intervention $(n=66)$. Non-melanoma skin cancers were removed $(n=20)$, resulting in a final sample of 46 cancer survivors for the current analysis. Flow of cancer survivors through the trial is illustrated in Fig. 1.

The intervention arm received the FlexToBa ${ }^{\mathrm{Tm}}$ DVD, two resistance bands of varying intensities, a yoga mat, and a FlexToBa ${ }^{\mathrm{Tm}}$ handbook. The DVD consisted of six progressive exercise sessions, one for each month of the program, each with 11-12 different exercises focused on flexibility, toning, and balance. The intervention was progressive in nature, both within and across the six months, such that the exercises 


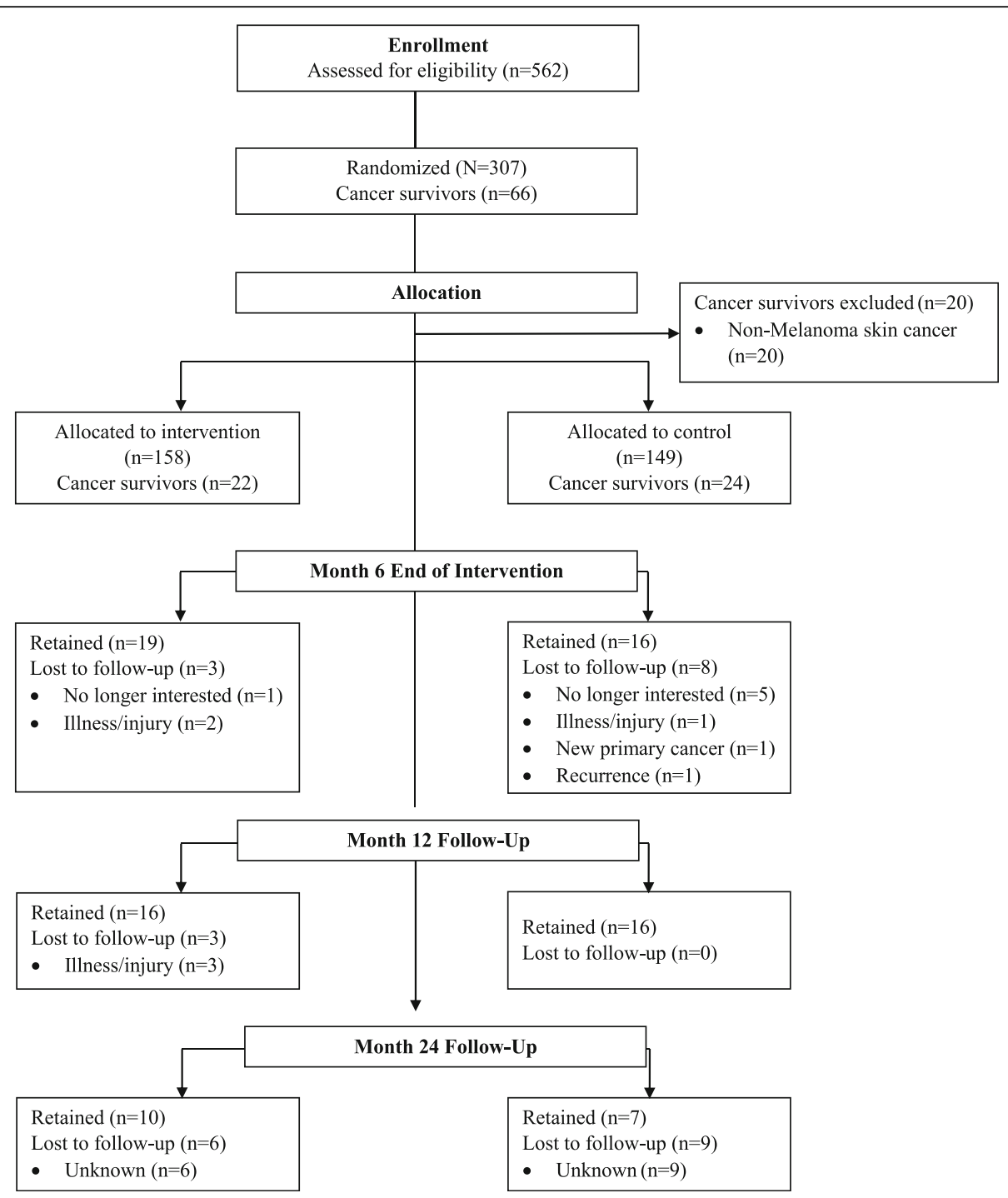

Fig. 1 CONSORT for cancer survivors enrolled in FlexToBa ${ }^{\text {TM }}$. Reasons for exclusions provided for cancer survivors only. Month 24 follow-up added after study initiation, reasons for exclusions not collected

built on themselves over the course of the intervention. A trained exercise leader led the exercises and was flanked by age-matched individuals demonstrating modified and challenging versions of the exercises. The control condition received a commerciallyavailable DVD by Dr. Andrew Weil, Healthy Aging, focused on generic health topics such as sleep, nutrition, exercise, and well-being. Both conditions received titrated support telephone calls from intervention staff over the course of the six months; these calls did not continue after formal intervention cessation. Study protocols were reviewed and approved by a university Institutional Review Board (approval $\# 09765)$ and all participants provided written informed consent prior to participation.

\section{Measures}

All measures were assessed at baseline, end of the intervention (six months), and after two no-contact follow-up periods (e.g., 12 and 24 months after baseline) by blinded research staff.

\section{Physical function}

The well-validated Short Physical Performance Battery (SPPB) [25] assessed balance, gait speed, and lower extremity strength through timed postural maintenance, timed 4-m walking, and timed chair stands, respectively. Performance scores for individual SPPB tests are provided along with a total summary score aggregating the individual tests. Also measured were upper body strength and endurance using an arm curl test (e.g., 
number of curls completed in $30 \mathrm{~s}$ ) and lower body flexibility with a sit and reach test (e.g., +/- inches from toes). Detailed methodology for these tests have been previously reported in the Senior Fitness Test Manual [26].

\section{Physical activity}

Physical activity was assessed objectively via accelerometry. Participants wore an Actigraph brand accelerometer (Actigraph, Pensacola, FL; Model GT1M or GT3X) on the non-dominant hip for 7 consecutive days and recorded the time spent wearing the accelerometer on a log. Data retained for analysis had $\geq 10 \mathrm{~h}$ of wear-time per day for at least 3 days when scored with an interruption period of $30 \mathrm{~min}$. Data were downloaded as activity counts, representing raw accelerations summed over a specific epoch length (e.g., $60 \mathrm{~s}$ ) and varied based on frequency and intensity. These data were then processed using older adult-specific cut-points [27]. Sedentary behavior is defined as $\leq 50 \mathrm{cpm}$, light physical activity is defined as $51-1040 \mathrm{cpm}$, and moderate-to-vigorous physical activity (MVPA) is defined as $\geq 1041 \mathrm{cpm}$. Total wear time was divided by the number of valid days to represent average daily counts/minute.

\section{Functional limitations}

The abbreviated function component of the Late-Life Function and Disability Instrument [28] assessed the degree of difficulty experienced by participants with basic and advanced lower and upper extremity function. Participants indicated the difficulty they would have with specific tasks on a 5-point Likert scale ranging from 5 (none) to 1 (cannot do). Subscales were combined to provide a total functional limitations score, such that lower scores indicated fewer difficulties when performing activities of daily living.

\section{Intervention components}

We further explored adherence to the intervention, assessed quantitatively as number of exercise days per month as reported by participants on home exercise logs. Satisfaction with different aspects of the intervention (e.g., exercise leader, DVD, research team) was measured on a Likert scale from 0 (dissatisfied) to 5 (very satisfied), and participants self-reported up to four benefits of the program (\% of sample reporting yes/no to each benefit). We also explored the number of adverse events to assess safety of the intervention after a cancer diagnosis.

\section{Data analysis}

Repeated measures mixed models assessed the effect of the intervention on functional health and physical activity outcomes over: (i) the 6-month intervention and (ii) the entire 24-month follow-up window. Time was calculated as months since baseline of the intervention. Fixed effects included time, group, and their interaction. Random effects were specified at the individual level. All models were estimated using restricted maximum likelihood (REML) method. Significance level for all models was set to 0.05 and all analyses were conducted using intent-to-treat in Stata version 16.1 (StataCorp, College Station, Texas). Across the entire sample, effects of the intervention did not differ in cancer survivors compared to cancer-free participants ( $p s>0.11$ ), therefore only cancer survivors were retained for analysis.

\section{Results}

Participant characteristics are detailed in Table 1.

Briefly, individuals were on average 73 years of age $\left[M_{\text {age }}=72.9 \pm 5.3\right], 80.4 \%$ female, and $93.5 \%$ White. Average body mass index of participants was $32.0 \pm 6.7$ and $32.6 \%$ resided in rural hometowns. The most commonly reported cancer type was breast (37.0\%), followed by melanoma (13.0\%). Other cancer types reported were: bladder, cervical, colon, Extramammary Paget's Disease, endometrial, fallopian tube, kidney, leukemia, lymphoma, prostate, thyroid, tongue, and uterine. Two participants reported multiple cancers and one reported recurrent cancer. Average time since diagnosis was $10.7 \pm 9.4$ years.

Table 1 Participant demographics \& cancer characteristics at baseline

\begin{tabular}{|c|c|c|c|}
\hline & $\begin{array}{l}\text { Total Sample } \\
N=46\end{array}$ & $\begin{array}{l}\text { FlexToBa } \\
n=22\end{array}$ & $\begin{array}{l}\text { Control } \\
n=24\end{array}$ \\
\hline & $M(S D)$ or $\%$ & $M(S D)$ or \% & $\mathrm{M}(\mathrm{SD})$ or $\%$ \\
\hline $\mathrm{Age}^{\dagger}$ & $72.9(5.3)$ & $72.1(5.6)$ & $73.6(5.0)$ \\
\hline Female & $80.4 \%$ & $68.2 \%$ & $91.7 \%$ \\
\hline White & $93.5 \%$ & $95.5 \%$ & $91.7 \%$ \\
\hline Body Mass Index & $32.0(6.7)$ & $32.6(7.3)$ & $31.4(6.2)$ \\
\hline Married & $62.2 \%$ & $61.9 \%$ & $62.5 \%$ \\
\hline Rural Hometown & $32.6 \%$ & $27.3 \%$ & $37.5 \%$ \\
\hline \multicolumn{4}{|l|}{ Cancer Type } \\
\hline Breast & $37.0 \%$ & $40.9 \%$ & $33.3 \%$ \\
\hline Colon & $6.5 \%$ & $9.1 \%$ & $4.2 \%$ \\
\hline Melanoma & $13.0 \%$ & $6.5 \%$ & $12.5 \%$ \\
\hline Prostate & $6.5 \%$ & $13.6 \%$ & $4.2 \%$ \\
\hline Other & $37.0 \%$ & $29.9 \%$ & $45.8 \%$ \\
\hline Time Since Diagnosis ${ }^{\dagger}$ & $10.7(9.4)$ & $10.4(8.1)$ & $11.0(10.6)$ \\
\hline Cardiovascular disease $\mathrm{Hx}^{*}$ & $2.8(1.7)$ & $2.6(1.6)$ & $2.9(1.8)$ \\
\hline Musculoskeletal pain $\mathrm{Hx}^{*}$ & $0.5(0.7)$ & $0.6(0.7)$ & $0.4(0.7)$ \\
\hline Pulmonary disease $\mathrm{Hx}^{*}$ & $0.2(0.4)$ & $0.1(0.4)$ & $0.2(0.4)$ \\
\hline
\end{tabular}

$\mathrm{M}=$ mean; $\mathrm{SD}=$ standard deviation; $\mathrm{Hx}=$ history

${ }^{\dagger}$ Years; ${ }^{*}$ Mean number of reported events 


\section{End of intervention (6-month)}

Repeated measures linear mixed models indicated a significant group*time interaction for the SPPB Total Score $(\beta=-1.14, p=0.048)$, driven by improved physical performance in the FlexToBa ${ }^{\mathrm{Tu}}$ group from baseline to end of intervention, compared with worsened performance in the control group. A similar trend was observed for the SPPB balance score, such that those in the intervention group had better balance at the end of the intervention $(\beta=-0.56, p=0.041)$. Trends for physical activity maintenance and decreased sedentary behavior in the intervention group emerged that, while not statistically significant $(p s>0.11)$, demonstrated meaningful effect sizes (light physical activity $d=-0.48$; MVPA $d=-0.22$; sedentary behavior $d=0.56$ ). We did not observe significant group*time differences for other measures of physical function or functional limitations $(p s>0.18)$. Full results from baseline to end of intervention are detailed in Table 2, and unadjusted mean data at baseline, end of intervention, and follow-up are detailed in Supplemental Table 1.

\section{Follow-ups (12- and 24-months)}

When examining the effects of the FlexToBa ${ }^{\mathrm{mm}}$ intervention over the follow-up period, similar patterns emerged for the SPPB Total score. The group"time interaction from 0 to 12 months trended towards improved function in the intervention group $(\beta=-0.97, p=0.089)$ and was significant from 0 to 24 months $(\beta=-1.84, p=0.012)$. Figure 2 depicts the 24-month trajectory. No further group differences were observed over the follow-up period for functional health $(p s>0.11)$.

\section{Intervention components}

No adverse events occurred in the sample of cancer survivors. Adherence in the exercise group gradually declined over the course of the intervention. Average exercise days for each month were as follows: month $1=12.0 \pm 3.0$; month $2=8.7 \pm 4.4 ;$ month $3=8.1 \pm 4.5$; month $4=7.0 \pm 5.2$; month $5=5.6 \pm 5.3$ and; month $6=$ $5.5 \pm 5.5$ days. Overall, participants in the FlexToBa $a^{\mathrm{mm}}$ group enjoyed the intervention. On a scale of 0 (dissatisfied) to 5 (very satisfied), average ratings of the exercise program, exercise leader, quality of the DVD, progression of the exercises, modifications available, testing appointments, support calls, and the FlexToBa ${ }^{\mathrm{m}}$ research team were all above 4.5 . The most common selfreported benefits of the program included physical health (43.5\%), mental health (13.0\%), and behavior regulation $(10.9 \%)$.

\section{Discussion}

Physical activity during cancer survivorship is widely encouraged but remains poorly implemented, particularly in both clinical and community settings [6, 27]. Our findings suggest that a DVD-delivered intervention originally designed for older adults provided significant improvements in functional health after cancer. Importantly, these effects were maintained over a year after the end of the intervention. These findings are consistent with the body of evidence documenting functional benefits with increased physical activity during cancer survivorship [1,2], and support the broad dissemination of general physical activity programs to long-term cancer survivors. However, our findings suggest that intervention tailoring is warranted for increasing physical activity levels and further optimizing health benefits during cancer survivorship.

Our finding of the positive effects of physical activity on functional health is consistent with the exercise oncology literature [8]. A consensus statement from an international multidisciplinary roundtable of experts documented there is strong evidence that physical activity improves physical functioning in cancer survivors [1]. However, more robust effects of exercise have been documented in supervised interventions [1], which may be due to the presence of other participants, trained personnel and social support, as well as home-based interventions' heavy reliance on self-reported measures with limited to no follow-up [7, 8]. This study documents the efficacy of a home-based exercise program for improving functional health, as assessed by the SPPB, after cancer with over a year of follow-up. Importantly, effects of the intervention did not differ between older adults and those with a history of cancer. The mean SPPB score in the intervention cancer group was a full point higher than the control cancer group at the end of the intervention, representing a clinically meaningful difference [29]. No adverse events occurred in this subsample of cancer survivors, highlighting the safety of such a program for this specific sample of survivors. Of course, it should be noted that this sample was comprised of long-term survivors (mean time since diagnosis $=10.7$ years) who were deemed healthy enough by their personal physicians to participate. Only 8 participants were less than two years from their cancer diagnoses, which limited our ability to determine if the intervention effects may have been modified by acute tumor- or treatment-related factors. While future work would do well to replicate these findings in cancer survivors who are in the early stage of their disease and/or closer to treatment, our findings have important public health and safety implications for the dissemination of general, home-based physical activity programs for longterm cancer survivors.

The successful DVD delivery of this intervention to cancer survivors has important connotations for extending our reach beyond university and clinical settings to a 
Table 2 Full linear mixed models results from baseline $(\mathrm{m} 0)$ to end of intervention $(\mathrm{m} 6)$

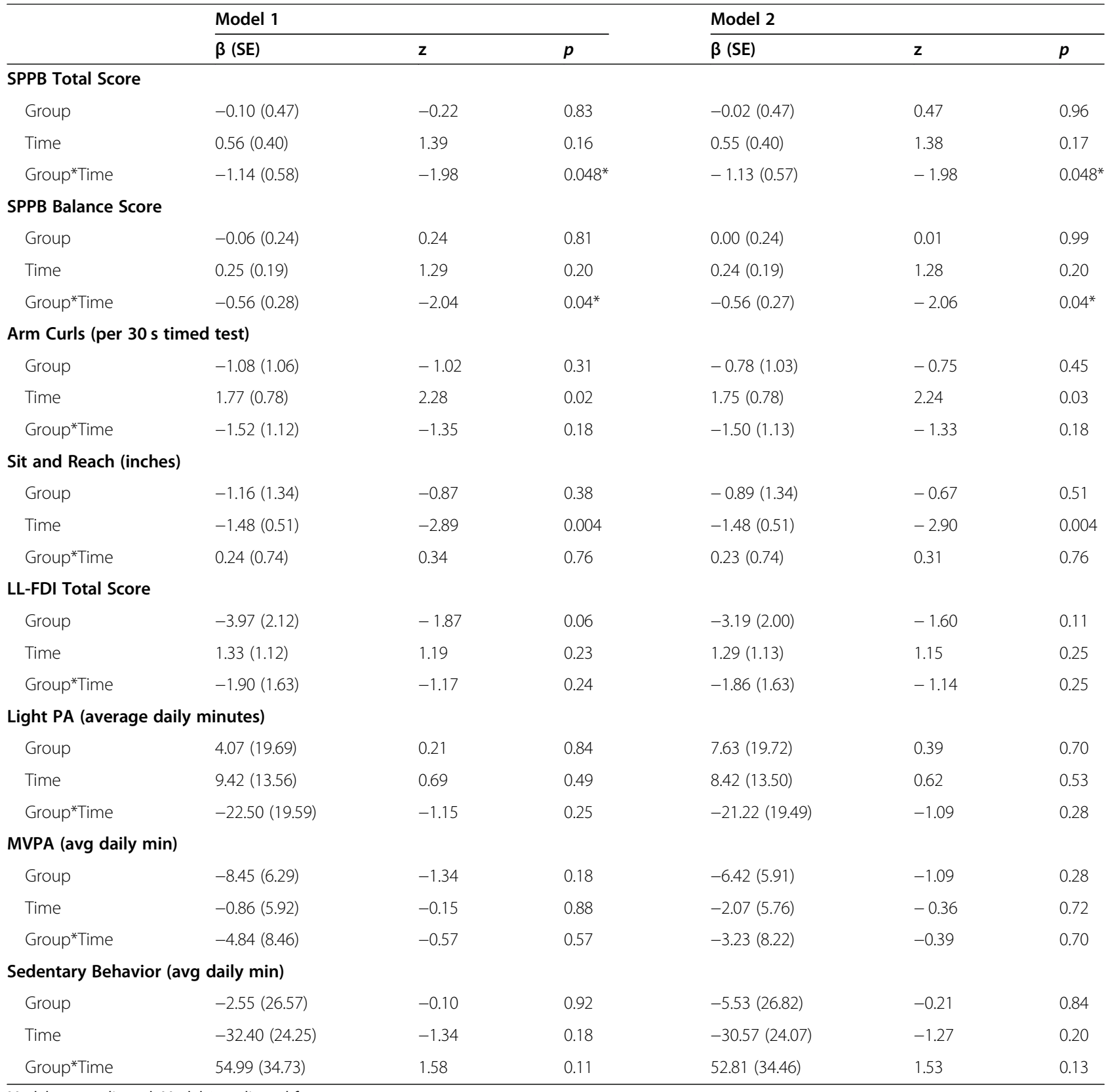

Model $1=$ unadjusted; Model $2=$ adjusted for age

$\mathrm{SE}=$ standard error; $\mathrm{SPPB}=$ Short Physical Performance Battery; $\mathrm{LL}-\mathrm{FDI}=$ functional limitations; $\mathrm{PA}=$ physical activity; $\mathrm{MVPA}=$ moderate to vigorous physical activity

broader range of survivors, including those who have limited healthcare access, a functional disability, and/or reside in rural environments. Recent research suggests that it may be a feasible and acceptable dissemination method in this population [29-31]. Indeed, several reviews have noted that most cancer survivors prefer to exercise at home with flexible programs that can be adapted to fit an individual's schedule; however, most survivors also prefer tailoring to cancer-specific content [7, 32]. Roberts and colleagues [7] further highlighted that while digitally-delivered behavior change interventions in cancer survivors can successfully increase physical activity levels across different platforms (e.g., website, mobile phone), the risk of bias and heterogeneity in these trials is high [33]. The present study included accelerometry and over two years of follow-up, but only 46 of the 307 participants in the original sample reported a history of cancer. There is a clear need for larger randomized controlled trials with objective measures of physical activity, long-term follow-up, and standardized measures of health [34]. Ideally, these trials would be designed with implementation in mind and 


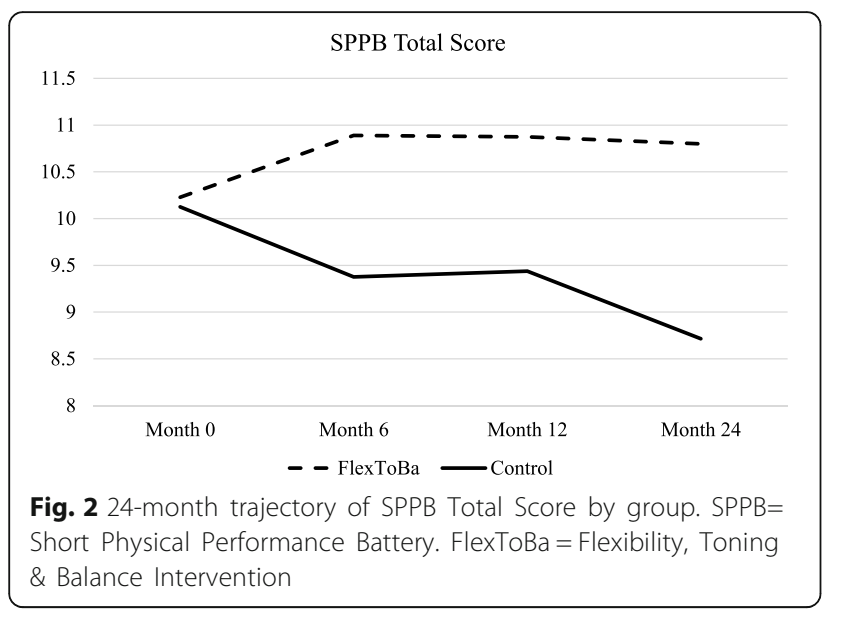

include: i) content specific to the cancer experience and symptomology for safety, comfort, and preference; ii) quantitative and qualitative feedback for further optimization and; iii) objective, generalizable measures of both physical activity and health outcomes, including those that are cancer specific, with long follow-up periods.

Despite the ease of delivering this intervention via DVD over a six-month period, it's unclear how this medium would be accepted over the next several years with new emerging technologies and growing geographic disparities after cancer [35]. This content may be readily transferrable to newer technologies such as smart phones or mobile applications (or even remain in DVD format); however, future work should seek to understand survivors' preferences about delivery mode and access to technology for home-based physical activity programs before making adaptations. While certain physical activity preferences have generally been well-studied in cancer survivors (e.g., physical activity modality, location, content) [36], less is known about the extent to which rural-dwelling survivors are able to access specific technologies required for digitally-delivered interventions (e.g., internet access, electronics ownership). A recent systematic review and RE-AIM evaluation of rural physical activity interventions indeed highlighted limited intervention effects and generalizability, likely due to poor reporting across trials [37]. While FlexToBa $a^{\text {tw }}$ was largely well-attended and received based on anonymized feedback, we were unable to determine how feedback varied between cancer survivors and the full sample, or in those rural-dwelling individuals with reduced access to technological support. Maintaining high levels of adherence in an unsupervised, rural environment is another important safety and efficacy concern as future efforts strive to deliver accessible interventions via technology. While adherence in this sample gradually declined over the course of the intervention, potentially due to tapered contact from research staff, participants were still engaging with the DVD more than once a week. More contemporary technologies would allow for real time, objective monitoring of usage patterns, which may be leveraged to promote adherence and ensure safety. If our goal is to bring physical activity benefits to all cancer survivors, more work is required to understand how to maximize and optimize our reach across cancer populations to promote equitable access.

Of further interest is the lack of significant intervention effects on objective physical activity and sedentary behavior in this sample of cancer survivors. FlexToBa ${ }^{\mathrm{mm}}$ placed a large emphasis on strengthening and balance exercises, and the current sample of cancer survivors was small; therefore, it is not surprising that we were unable to detect significant changes in aerobic physical activity. Our effect sizes do indicate, however, that programs like FlexToBa ${ }^{\text {th }}$ may still be meaningful and important for physical activity profiles. Strengthening and balance are important in the context of fall prevention after treatment for breast cancer [38], especially in older survivors. To optimize health and activity improvements based on recommendations by the Department of Health and Human Services [39], future interventions would benefit from including a walking component. Most survivors are physically capable of walking and have identified it as a preferred modality for physical activity programs [36], making it a feasible and clearly desirable addition to technologically-delivered home-based interventions like FlexToBa ${ }^{\mathrm{m}}$.

These findings should be interpreted in the context of their strengths and limitations. While the current sample included fewer than 50 individuals with a history of cancer, FlexToBa ${ }^{\mathrm{Tt}}$ is a large, randomized controlled exercise trial with a theoretical framework, objective measures of physical activity and health, and long follow-up periods: a solid foundation for future trials to build upon. Participants self-reported their adherence to the intervention, which may introduce social desirability bias, and their cancer diagnoses; no information on treatment regimen or cancer stage was available. These effects may be different in survivors of different stages, times since diagnosis, and/or treatment regimens. Nonetheless it is encouraging that a physical activity intervention originally designed for older adults was capable of improving functional health in long-term cancer survivors. The current sample was predominantly female, which is unsurprising given that there are proportionately more women aged 65 years and older than men; however, we were unable to recruit a larger percentage of minority participants despite our increased recruitment efforts in areas with higher numbers of minority adults. These findings should be replicated in larger samples of more racially and geographically diverse cancer populations to 
better understand how physical activity can be successfully implemented into different communities. Additional tailoring may be warranted to reach minority populations to ensure that all survivors can receive physical activity benefits.

\section{Conclusions}

We observed similar benefits in the effects of a DVDdelivered physical activity intervention on physical function between older adults and those with a history of cancer. In cancer survivors specifically, those in the intervention arm demonstrated significant improvements in functional performance compared to those in the control condition. These findings point to the need for risk stratification during cancer survivorship so that low-risk survivors can be guided to general physical activity programs such as FlexToBa $a^{\text {Ta }}$ for improved and maintained health during long-term survivorship. Further cancer-specific adaptations may be necessary to maximize health benefits of these home-based programs, and it remains of paramount importance to increase access and adherence to physical activity programs for survivors in low-resource settings for improved health and longevity.

\section{Abbreviations \\ FlexToBa'T: Flexibility, toning, and balance trial; SPPB: Short Physical Performance Battery; MVPA: moderate to vigorous physical activity; RE- AIM: Reach, Effectiveness, Adoption, Implementation, Maintenance; MS: multiple sclerosis; REML: restricted maximum likelihood estimation; M: mean; SD: standard deviation; SE: standard error; LL-FDI: functional limitations}

\section{Supplementary Information}

The online version contains supplementary material available at https://doi. org/10.1186/s12885-021-08608-8.

\section{Additional file 1.}

\section{Acknowledgements}

The authors express their sincere appreciation to Susan H. Houseworth, MS, project coordinator for this study; Bill Yauch and RiellyBoy Productions; Erica Urrego, DVD exercise leader; and Grant Henry, Lynda Matejkowski, Joyce O'Donnell, Bernard Puglisi, Paula Smith, and Peter Tan, our DVD exercise models. The authors also extend their thanks to Andrew Weil, MD, for the generous contribution of the Healthy Aging DVDs.

\section{Authors' contributions}

ES and EM made substantial contributions to conception and design of the current analysis. ES, NG, JF \& EM collected data. ES formally analyzed and interpreted the data. LP \& GC provided cancer-specific data interpretations. ES drafted the initial manuscript. All authors revised the manuscript critically for important intellectual content. All authors read and approved the final manuscript.

\section{Funding}

This work was supported by the National Institute on Aging at the National Institutes of Health (2R01 AG20118). The funding body played no role in the design of the study and collection, analysis, and interpretation of data and in writing the manuscript.

\section{Availability of data and materials}

The datasets used and/or analyzed during the current study will be made available upon reasonable request from the corresponding author; the data are not publicly available due to privacy or ethical restrictions.

\section{Declarations}

Ethics approval and consent to participate

All methods and procedures were approved by the institutional review board (IRB; ethics committee) at the University of Illinois at Urbana-

Champaign (approval \#09765), and written informed consent was obtained from all included participants prior to study initiation.

\section{Consent for publication}

N/A

\section{Competing interests}

The authors declare no competing interests.

\section{Author details}

${ }^{1}$ Division of Public Health Sciences, Department of Surgery, Washington University School of Medicine in St. Louis, St. Louis, USA. ${ }^{2}$ Department of Kinesiology \& Community Health, University of Illinois at Urbana-Champaign, Champaign, USA. ${ }^{3}$ Beckman Institute for Advanced Science and Technology, University of Illinois at Urbana-Champaign, Champaign, USA. ${ }^{4}$ Department of Health \& Exercise Science, Wake Forest School of Medicine, Winston-Salem, USA. ${ }^{5}$ Division of Medical Oncology, Department of Medicine, Washington University School of Medicine in St. Louis, St. Louis, USA.

Received: 8 April 2021 Accepted: 16 July 2021

Published online: 29 July 2021

\section{References}

1. Campbell $\mathrm{KL}$, et al. Exercise guidelines for Cancer survivors: consensus statement from international multidisciplinary roundtable exercise guidelines for Cancer survivors: consensus statement from international multidisciplinary roundtable SPECIAL COMMUNICATIONS. Med Sci Sport Exerc. 2019;51(11):2375-90. https://doi.org/10.1249/MSS.0000000000002116.

2. Patel AV, Friedenreich CM, Moore SC, Hayes SC, Silver JK, Campbell KL, Matthews CE. American College of Sports Medicine roundtable report on physical activity, sedentary behavior, and cancer prevention and control. Med Sci Sports Exerc. 2019;51(11):2391.

3. Lahart IM, Metsios GS, Nevill AM, Carmichael AR. Physical activity, risk of death and recurrence in breast cancer survivors: a systematic review and meta-analysis of epidemiological studies. Acta oncologica. 2015;54(5):635-54.

4. Speck RM, Courneya KS, Mâsse LC, Duval S, Schmitz KH. An update of controlled physical activity trials in cancer survivors: a systematic review and meta-analysis. J Cancer Surviv. 2010;4(2):87-100. https://doi.org/10.1007/s11 764-009-0110-5.

5. White SM, McAuley E, Estabrooks PA, Courneya KS. Translating physical activity interventions for breast Cancer survivors into practice: an evaluation of randomized controlled trials. Ann Behav Med. Feb. 2009;37(1):10-9. https://doi.org/10.1007/s12160-009-9084-9.

6. Alfano CM, et al. NCl Funding Trends and Priorities in Physical Activity and Energy Balance Research Among Cancer Survivors. JNCl. 2016;108(1):285. https://doi.org/10.1093/jnci/djv285.

7. Roberts AL, Fisher A, Smith L, Heinrich M, Potts HW. Digital health behaviour change interventions targeting physical activity and diet in cancer survivors: a systematic review and meta-analysis. Journal of Cancer Survivorship. 2017;11(6):704-719.

8. Swartz MC, Lewis ZH, Lyons EJ, Jennings K, Middleton A, Deer RR, Goodwin JS. Effect of home-and community-based physical activity interventions on physical function among cancer survivors: a systematic review and metaanalysis. Archives of physical medicine and rehabilitation. 2017;98(8):165265.

9. Guida JL, Ahles TA, Belsky D, Campisi J, Cohen HJ, DeGregori J, Hurria A. Measuring aging and identifying aging phenotypes in cancer survivors. JNCl: Journal of the National Cancer Institute. 2019;111(12):1245-54

10. Henderson TO, Ness KK, Cohen HJ. Accelerated aging among cancer survivors: from pediatrics to geriatrics. American Society of Clinical Oncology Educational Book. 2014;34(1):e423-e430. 
11. McAuley E, Wójcicki TR, White SM, Mailey EL, Szabo AN, Gothe N, et al. Physical activity, function, and quality of life: design and methods of the FlexToBa TM trial. Contemp Clin Trials. 2012;33(1):228-36. https://doi.org/1 0.1016/j.cct.2011.10.002.

12. Bandura A. Social cognitive theory: an agentic perspective. Annu Rev Psychol. Feb. 2001;52(1):1-26. https://doi.org/10.1146/annurev.psych.52.1.1.

13. Glasgow RE, Vogt TM, Boles SM. Evaluating the public health impact of health promotion interventions: the RE-AIM framework. Am J Public Health. 1999;89(9):1322-7.

14. Fanning J, Porter G, Awick EA, Wójcicki TR, Gothe NP, Roberts SA, McAuley E. Effects of a DVD-delivered exercise program on patterns of sedentary behavior in older adults: a randomized controlled trial. Prev Med Rep. 2016; 3:238-43.

15. McAuley E, Wojcicki TR, Gothe NP, Mailey EL, Szabo AN, Fanning J, et al. Effects of a DVD-delivered exercise intervention on physical function in older adults. J Gerontol A Biol Sci Med Sci. 2013;68(9):1076-82. https://doi. org/10.1093/gerona/glt014.

16. Awick EA, Ehlers D, Fanning J, Phillips SM, Wójcicki T, Mackenzie MJ, McAuley E. Effects of a home-based DVD-delivered physical activity program on self-esteem in older adults: Results from a randomized controlled trial. Psychosom Med. 2017;79(1):71.

17. Fanning J, Awick EA, Wójcicki TR, Gothe N, Roberts S, Ehlers DK, McAuley E. Effects of a DVD-delivered exercise intervention on maintenance of physical activity in older adults. J Phys Act Health. 2016;13(6):594-8.

18. Roberts S, Awick E, Fanning JT, Ehlers D, Motl RW, McAuley E. Long-term maintenance of physical function in older adults following a DVD-delivered exercise intervention. J Aging Phys Act. 2017;25(1):27-31.

19. Wójcicki TR, Fanning J, Awick EA, Olson EA, Motl RW, McAuley E. Maintenance effects of a DVD-delivered exercise intervention on physical function in older adults. J Gerontol A Biol Sci Med Sci. 2015;70(6):785-9.

20. Gothe NP, Wójcicki TR, Olson EA, Fanning J, Awick E, Chung HD, McAuley E. Physical activity levels and patterns in older adults: the influence of a DVDbased exercise program. J Behav Med. 2015;38(1):91-97.

21. Aguiñaga S, Ehlers DK, Salerno EA, Fanning J, Motl RW, McAuley E. Homebased physical activity program improves depression and anxiety in older adults. J Phys Act Health. Sep. 2018;15(9):692-6. https://doi.org/10.1123/jpa h.2017-0390.

22. McAuley E, Wójcicki TR, Learmonth YC, Roberts SA, Hubbard EA, KinnettHopkins D, et al. Effects of a DVD-delivered exercise intervention on physical function in older adults with multiple sclerosis: a pilot randomized controlled trial. Mult Scler J - Exp Transl Clin. 2015;1:205521731558483. https://doi.org/10.1177/2055217315584838.

23. Salerno EA, Saint-Maurice PF, Willis EA, Moore SC, DiPietro L, Matthews CE. Ambulatory function and mortality among cancer survivors in the $\mathrm{NIH}$-AARP diet and health study. Cancer Epidemiol Biomark Prev. Apr. 2021;30(4):6908. https://doi.org/10.1158/1055-9965.EPI-20-1473.

24. Harden SM, Fanning JT, Motl RW, McAuley E, Estabrooks PA. Determining the reach of a home-based physical activity program for older adults within the context of a randomized controlled trial. Health Educ Res. Oct. 2014; 29(5):861-9. https://doi.org/10.1093/her/cyu049.

25. Guralnik JM, Simonsick EM, Ferrucci L, Glynn RJ, Berkman LF, Blazer DG, et al. A short physical performance battery assessing lower extremity function: association with self-reported disability and prediction of mortality and nursing home admission. J Gerontol. 1994;49(2):M85-94. https://doi. org/10.1093/geronj/49.2.M85.

26. Rikli RE, Jones CJ. Senior fitness test manual. Hum Kinet. 2013.

27. Copeland JL, Esliger DW. Accelerometer assessment of physical activity in active, healthy older adults. J Aging Phys Act. 2009;17(1):17-30. https://doi org/10.1123/japa.17.1.17

28. Jette AM, Haley SM, Coster WJ, Kooyoomjian JT, Levenson S, Heeren T, et al Late life function and disability instrument: I. development and evaluation of the disability component. J Gerontol - Ser A Biol Sci Med Sci. 2002;57(4): M209-16. https://doi.org/10.1093/gerona/57.4.M209.

29. Kwon S, Perera S, Pahor M, Katula JA, King AC, Groessl EJ, et al. What is a meaningful change in physical performance? Findings from a clinical trial in older adults (the LIFE-P study). J Nutr Heal Aging. 2009;13(6):538-44. https:// doi.org/10.1007/s12603-009-0104-Z.

30. IJsbrandy C, Hermens RPMG, Boerboom LWM, Gerritsen WR, van Harten WH, Ottevanger PB. Implementing physical activity programs for patients with cancer in current practice: patients' experienced barriers and facilitators. J Cancer Surviv. Oct. 2019;13(5):703-12. https://doi.org/10.1007/ s11764-019-00789-3.

31. Marthick M, Janssen A, Cheema BS, Alison J, Shaw T, Dhillon H. Feasibility of an Interactive Patient Portal for Monitoring Physical Activity, Remote Symptom Reporting, and Patient Education in Oncology: Qualitative Study. JMIR Cancer. 2019;5(2):e15539. https://doi.org/10.2196/15539.

32. Phillips SM, Conroy DE, Keadle SK, Pellegrini CA, Lloyd GR, Penedo FJ, et al. Breast cancer survivors' preferences for technology-supported exercise interventions. Support Care Cancer. Oct. 2017;25(10):3243-52. https://doi. org/10.1007/s00520-017-3735-3.

33. Mishra SI, Scherer RW, Snyder C, Geigle PM, Berlanstein DR, Topaloglu O. Exercise interventions on health-related quality of life for people with cancer during active treatment. In: Mishra SI, editor. Cochrane database of systematic reviews. Chichester: John Wiley \& Sons, Ltd; 2012.

34. Cella D, Riley W, Stone A, Rothrock N, Reeve B, Yount S, et al. The patientreported outcomes measurement information system (PROMIS) developed and tested its first wave of adult self-reported health outcome item banks: 2005-2008. J Clin Epidemiol. 2010;63(11):1179-94. https://doi.org/10.1016/j. jclinepi.2010.04.011.

35. Yabroff KR, Han X, Zhao J, Nogueira L, Jemal A. Rural Cancer disparities in the United States: a multilevel framework to improve access to care and patient outcomes. JCO Oncol Pract. 2020;16(7):409-13. https://doi.org/10.12 00/op.20.00352.

36. Wong JN, McAuley E, Trinh L. Physical activity programming and counseling preferences among cancer survivors: a systematic review. Int I Behav Nutr Phys Act. 2018;15(1):1-21.

37. Bhuiyan N, Singh P, Harden SM, Mama SK. Rural physical activity interventions in the United States: a systematic review and RE-AIM evaluation. Int J Behav Nutr Phys Act. 2019;16(1):1-11.

38. Chen Z, Maricic M, Aragaki AK, Mouton C, Arendell L, Lopez AM, et al. Fracture risk increases after diagnosis of breast or other cancers in postmenopausal women: results from the Women's health initiative. Osteoporos Int. 2009;20(4):527-36. https://doi.org/10.1007/s00198-0080721-0.

39. Piercy KL, et al. The Physical Activity Guidelines for Americans. JAMA. 2018; 320(19):2020. https://doi.org/10.1001/jama.2018.14854.

\section{Publisher's Note}

Springer Nature remains neutral with regard to jurisdictional claims in published maps and institutional affiliations.
Ready to submit your research? Choose BMC and benefit from:

- fast, convenient online submission

- thorough peer review by experienced researchers in your field

- rapid publication on acceptance

- support for research data, including large and complex data types

- gold Open Access which fosters wider collaboration and increased citations

- maximum visibility for your research: over $100 \mathrm{M}$ website views per year

At BMC, research is always in progress.

Learn more biomedcentral.com/submissions 